\title{
Characteristics Analysis of Precipitation Observations and Climate Change Along the High-speed Railway in Jiangsu
}

Qidong Zhang ${ }^{1}$, Xiong Xiong ${ }^{2 *}$, Xin Chen ${ }^{2}$, Xiaogen Kong ${ }^{3}$, Qinyu Qiu ${ }^{3}$, Xueming Xu${ }^{4}$

${ }^{1}$ State Grid Jiangsu Maintenance Company, Nanjing 211102, China

${ }^{2}$ Jiangsu Collaborative Innovation Center of Atmospheric Environment and Equipment Technology, Nanjing University of Information Science and Technology, Nanjing 210044, China

${ }^{3}$ China Railway Nanchang Bureau Group Co., Ltd., Nanchang 330002, China

${ }^{4}$ Jiangsu Tobacco Corporation, Nanjing 210018, China

*to whom all correspondence should be addressed: e-mail: nxgxiong@163.com

\section{GRAPHICAL ABSTRACT}

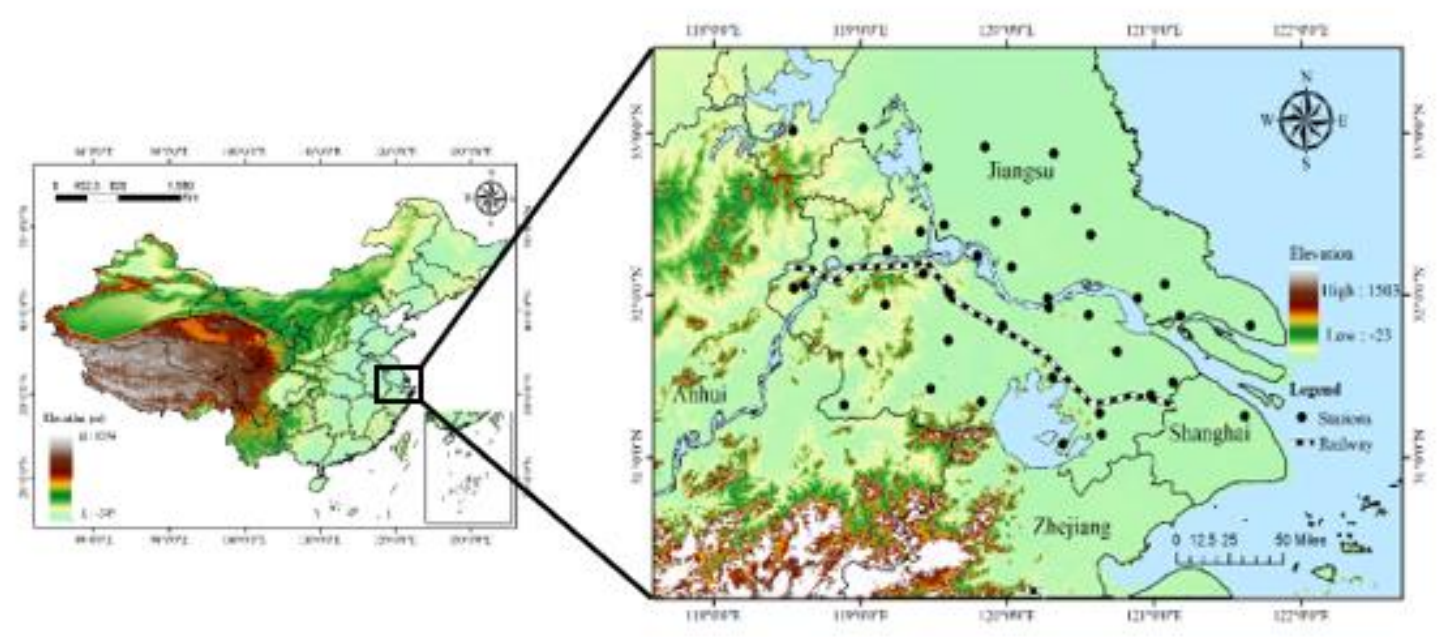

\section{ABSTRACT}

High-speed railway (HSR) is severely affected by precipitation disasters. There are many studies on precipitation and precipitation disasters, most of which are precipitation and analysis of disasters caused by precipitation, and few explain climate changes caused by precipitation. This study explores possible precursor conditions that might be employed for predicting the upcoming occurrence of extreme precipitation events. Surface meteorological observation data within $90 \mathrm{~km}$ along the Jiangsu section of the Beijing-Shanghai HSR is used to characterize the coupling relation among precipitation, air pressure and temperature. The results of the study shows that there is a strong correlation between heavy precipitation, extreme precipitation, and temperature and pressure within 2 to 6 hours before the occurrence of an extreme precipitation event. This conclusion is conducive to the operation of the HSR.

Keywords: High-speed railway, Precipitation analysis, Extreme precipitation, Precursors for precipitation events, Correlation analysis

\section{Introduction}

HSR is developing rapidly which has become one of the main transportation modes for people to travel due to its fast and convenient. Chinese HSR operating mileage has exceeded $35000 \mathrm{~km}$, accounting for $25.18 \%$ and nearly $70 \%$ of total HSR length in other counties, ranking first in the world (Ren et al., 2020). With the 
development of economy and technology, people have put forward higher requirements for the speed and safety performance of HSR operation. Engineering issues, such as ground vibration, subgrade expansion, track wear, etc. will affect the safe operation (Guo et al., 2019; Skrypnyk et al., 2019; Xiao et al., 2020). In addition, the safety of the meteorological environment during HSR operation cannot be ignored. On August 10, 2019, 31 high-speed trains were suspended from Zhengzhou East Railway Station due to the impact of Typhoon "Lichma". The harsh weather environment restricts the operating efficiency of high-speed rail, which brings a lot of economic losses (Zuo et al., 2020).

Intensification of extreme precipitation due to a warming climate is of considerable societal concern, with resultant floods being one of the most common, dangerous, and destructive HSR disasters. Extreme precipitation can not only directly damage railways and trains, but also a variety of natural disasters such as floods, mudslides, and landslides induced by continuous precipitation can even have more serious impacts on the safety and operation of the railway system (Hu et al., 2020). Sufficient inspections have been made on the long-term trend of extreme precipitation events (Yao et al., 2008), specific extreme event case analysis (Durkee et al., 2012), and extreme precipitation characteristics in specific regions (Bocheva et al., 2009; Liebmann et al., 2001; Zhang et al., 2001). Many studies have mentioned that extreme precipitation events occur more frequently (Lehmann et al., 2015). Wan et al. (2017) pointed out that the Qinghai-Tibet Plateau regulates largescale atmospheric circulation and water vapor transport in southern China, and its surface heat enhances the high-pressure system on the Yangtze River Plain and prevents precipitation from moving northward. Kunkel et al. (2012) conducted a statistical analysis of seven meteorological causes caused by observed extreme precipitation events, among which extreme precipitation events caused by frontal and tropical cyclones have increased. Teixeira et al. (2014) used WRF to simulate precipitation driven by different terrains of Madeira Island. The precipitation pattern over Madeira Island is related to the terrain of different simulation fields. Disasters caused by regional continuous extreme precipitation events are more serious. Chen and Zhai (2013) considered the continuity and extremeness of daily precipitation at various meteorological stations and designed a method for identifying regional continuous extreme events. Hina et al. (2021) analyzed the possible cycles and precursor conditions of the upcoming drought in Pakistan and pointed out that the wind vector from March to May as a precursor can be used to predict the occurrence of drought in Pakistan. Jennrich et al. (2020) studied the identification of synoptic patterns and precursors ahead of an extreme precipitation event over the contiguous United States.

The above-mentioned literature reports many studies on the characteristics of precipitation at national and regional scales, but rarely studies the precursor conditions related to the occurrence of heavy precipitation. Therefore, it is essential to conduct new research and analysis on climatic parameters, with the aim of using their status as a prediction tool for heavy precipitation. This paper uses surface observation data to study the relationship between temperature, precipitation and air pressure along a certain section of the Beijing-Shanghai high-speed railway in China (Xu et al., 2020). The data is collected from ground automatic meteorological stations within $90 \mathrm{~km}$ of the section. Regarding all the precipitation events that occurred in $2016 \sim 2018$, two issues were concerned: 1) Can the changes of air pressure and temperature along the high-speed rail indicate the occurrence of precipitation events? 2) Are different levels of precipitation events related to changes in air pressure or temperature before the event?

The arrangement of the article is as follows: Data and methods used in this study are described in section 2. Section 3 introduces the research ideas and the flow chart. The relationship between precipitation and other Meteorological elements is arranged in section 4. Finally, conclusions and a discussion of results are provided in section 5 . 


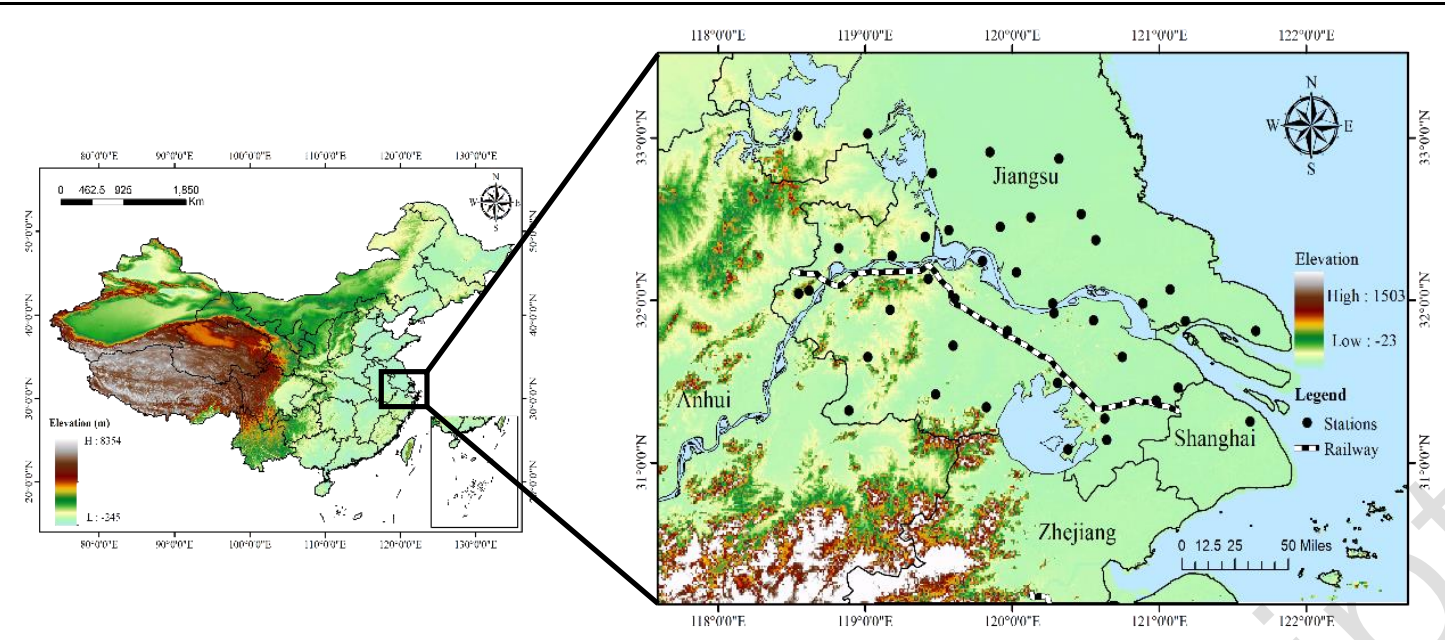

Figure 1. Distribution of meteorological stations along the railway

\section{Data and method}

\subsection{Data}

The analysis focused on the Jiangsu section of the Beijing-Shanghai high-speed rail (specifically, the section from Nanjing to Suzhou). This section is located in the plains of the middle and lower reaches of the Yangtze River. The precipitation in the area is mainly concentrated in summer. Due to the flat terrain in this area, the terrain cannot bring uplifting effect to the air mass. Precipitation is mainly caused by the large amount of water vapor carried by the subtropical high-pressure air masses in the western Pacific Ocean moving to the land, generating cooling and heating masses between the continent and the ocean, and producing frontal rain (Pishtiwan and Khadija, 2019). The strength and location of this air mass roughly determines the amount of summer rainfall. The climate change and its anomalies in this region have received a lot of attention (Niu et al., 2018; Wang et al., 2015; Zheng and Zhao, 2005).

The observation data used in this study comes from the National Meteorological Center, includes 5minute observations of surface temperature, air pressure, relative humidity and rainfall at 70 stations in Jiangsu Province in $2016 \sim 2018$. Dataset has passed traditional quality control to eliminate obvious gross errors. The dataset provides a high resolution and comprehensive survey of meteorological elements. Table 1 shows the meteorological stations, the number of precipitation events, and annual precipitation along the high-speed railway in $2016 \sim 2018$.

Table 1. Statistics of meteorological stations along the high-speed rail

\begin{tabular}{llll}
\hline & $\begin{array}{l}\text { Station } \\
\text { number }\end{array}$ & $\begin{array}{l}\text { Number of } \\
\text { precipitation } \\
\text { events }\end{array}$ & $\begin{array}{l}\text { Annual } \\
\text { precipitation } \\
\text { intensity }(\mathrm{mm})\end{array}$ \\
\hline $\begin{array}{l}\text { North of the high-speed } \\
\text { rail line }\end{array}$ & 28 & 3777 & 758.53 \\
$\begin{array}{l}\text { South of the high-speed } \\
\text { rail line }\end{array}$ & 13 & 2116 & 260.68 \\
\hline
\end{tabular}

\subsection{Method}

As the high-speed rail is easily affected by heavy rainfall, this paper first analyzes the characteristics of precipitation along the railway, using the number of precipitation events, average annual precipitation, maximum daily precipitation, and maximum hourly precipitation intensity to characterize precipitation characteristics (Twumasi et al., 2019). Secondly, the relationship among precipitation, air pressure and 
temperature in the study area is discussed. The relationship between air pressure, temperature and hourly precipitation probability (POP) in $2016 \sim 2018$ is displayed graphically taking into account the differences between the whole year and the month.

The process of a precipitation is affected by multiple factors such as geographic location, atmospheric circulation and weather system. Due to different precipitation processes and different amounts of precipitation, the overall statistical results tend to exclude detailed information. In order to explore the relationship between air temperature, air pressure and precipitation before the occurrence of rain under different rainfall levels in more detail. According to Cai Yao's research, precipitation events are divided into three categories according to precipitation: extreme precipitation ( $>50 \mathrm{~mm}$ per day), heavy precipitation ( $25-50 \mathrm{~mm}$ per day) and mild to moderate precipitation ( $<25 \mathrm{~mm}$ per day) (Yao et al., 2008). Obtained the pressure change (PC) and the temperature change (TC) during the period of time before each precipitation event in the study area, as well as the sum of the hourly changes, to obtain the total pressure change and the total temperature change. The pressure change value and temperature change value $n$ hours before the precipitation event are defined as follows:

$$
\begin{aligned}
& P C \mathrm{n}=P\left(t_{n}\right)-P\left(t_{0}\right) \\
& T C \mathrm{n}=T\left(t_{n}\right)-T\left(t_{0}\right)
\end{aligned}
$$

where $t_{0}$ represents the moment when the event occurred. $t_{n}$ represents the nth hour before the event,

$\mathrm{n} \in\{1,2,3,6,12,24\}$.

The total pressure and temperature changes in the $\mathrm{n}$ hours before the precipitation event are defined as follows:

$$
\begin{aligned}
& T P C \mathrm{n}=\sum_{i=1}^{\mathrm{n}} P\left(t_{i}\right)-P\left(t_{0}\right) \\
& T T C \mathrm{n}=\sum_{i=1}^{\mathrm{n}} T\left(t_{i}\right)-T\left(t_{0}\right)
\end{aligned}
$$

where $t_{0}$ represents the moment when the event occurred. $t_{i}$ indicates the hour before the event, $\mathrm{n} \in\{1,2,3,6,12,24\}$

\section{Structure and flow chart of the present study}

Firstly, this paper analyzes regional precipitation characteristics from four indicators: annual average precipitation events, annual average precipitation, maximum daily precipitation, and maximum hourly precipitation intensity. Secondly, explore the relationship between air pressure and temperature and the probability of precipitation are explored. Finally, the relationship between air pressure and temperature before the precipitation event is given. The overall flow chart is shown in Figure 2. The whole experiment is implemented on the personal computer with AMD Ryzen R5-5600X six-core processor $3.70 \mathrm{GHZ}$ of CPU, 16 GB of RAM and single NIVIDIA GeForce RTX 2060 of GPU. Among the modules implemented in this study, trend analysis, curve fitting and correlation analysis are implemented with PYTHON. 

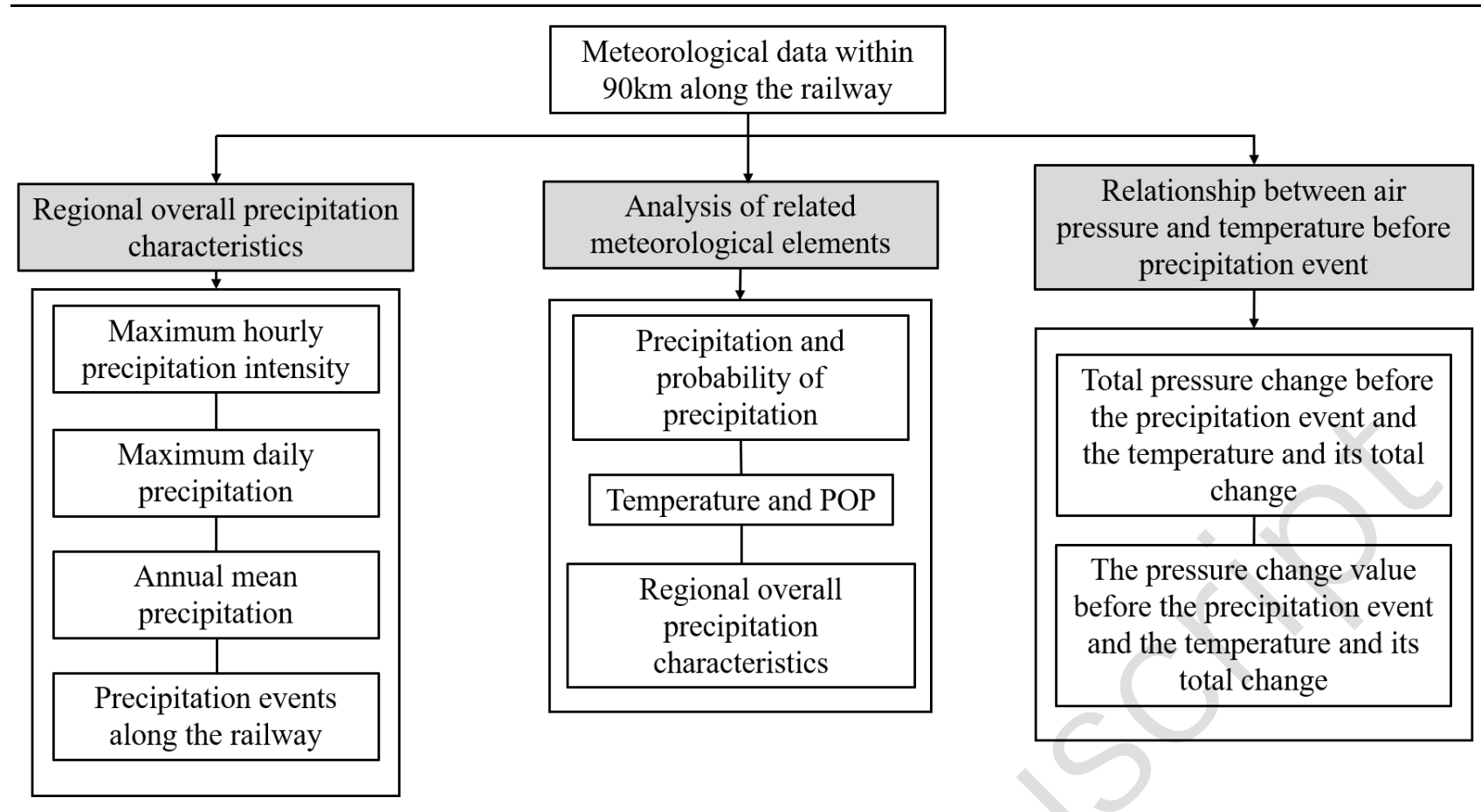

Figure 2. Flow chart of the present study

\section{Results and analysis}

\subsection{Regional precipitation characteristics}

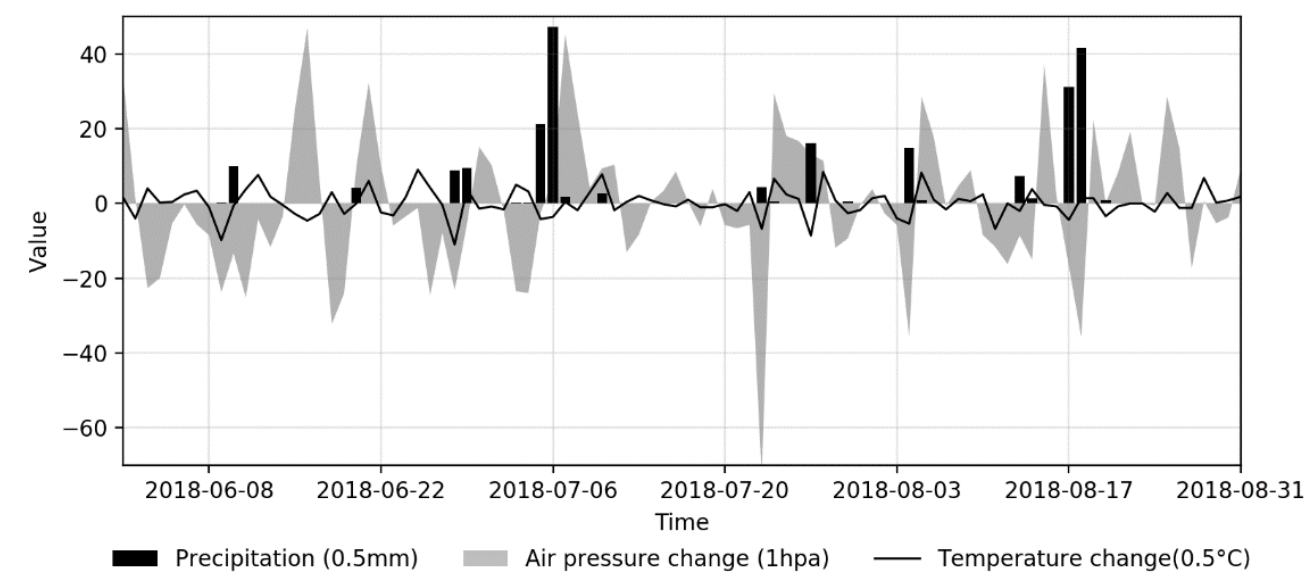

Figure 3. Nanjing Station June 1, 2018-August 31, 2018 Pressure change events and precipitation

There is a total of 41 meteorological stations within a $90 \mathrm{~km}$ range along the high-speed rail. The overall precipitation in 2018 reached $1343.7 \mathrm{~mm}$, which was a year of abundant rain. Figure 3 shows the pressure change events and precipitation at Nanjing Station (station number: 58 238) from June 1, 2018 to August 31, 2018. In the figure, the black columnar shadow represents the precipitation of the order of $0.5 \mathrm{~mm}$, the gray shadow represents the change of atmospheric pressure, and the black solid line represents the change of temperature. The gray shaded area above the 0 tick mark is defined as rising air pressure change event, and below 0 tick mark is defined as falling air pressure change event (Yu et al., 2018). Compared with rising events, falling events have higher hourly POP and precipitation depth. It is generally believed that when the daily average temperature is lower than $25^{\circ} \mathrm{C}$, with the influences affected by the Clausius-Clapeyron (CC) relationship, for every $1{ }^{\circ} \mathrm{C}$ increase in temperature, the water holding capacity in the atmosphere will increase by about $7 \%$, and extreme precipitation will also have the same increase in volume (Trenberth et al., 2003). 


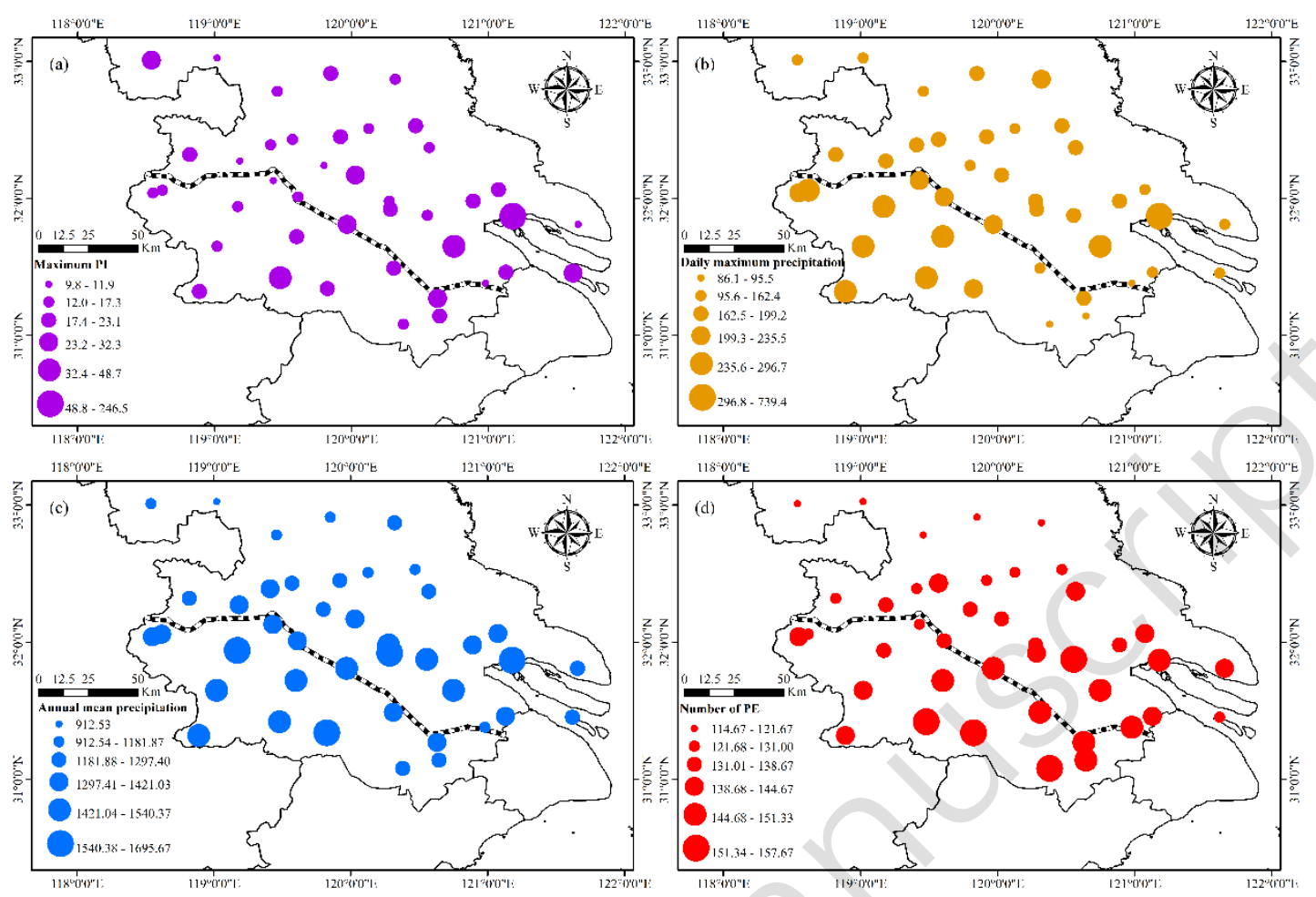

Figure 4. (a) Maximum hourly precipitation intensity (b) Maximum daily precipitation (c) Annual mean precipitation

(d) Precipitation events along the railway

Figure 4 shows that the area with frequent annual precipitation events along the railway line is located in the southeast part of the high-speed railway line, and the area with larger annual precipitation along the highspeed railway line is in the middle of the line. Among the 41 stations, the maximum values of annual average precipitation event volume, annual average precipitation, maximum daily precipitation, and maximum hourly precipitation intensity are $157.67,1695.67 \mathrm{~mm}, 739.54 \mathrm{~mm}$, and $246.5 \mathrm{~mm} / \mathrm{h}$, respectively, and the corresponding minimums are respectively $114.67,912.53 \mathrm{~mm}, 86.1 \mathrm{~mm}$ and $9.8 \mathrm{~mm} / \mathrm{h}$. There is a huge difference between the highest value and the lowest value. The areas with high daily maximum precipitation are concentrated in the southwest part of the figure, and the maximum precipitation intensity is concentrated in the southeast part along the line. Generally speaking, most of the precipitation in the region is concentrated along the high-speed rail. There is a large number of precipitation events along the southeast part of the line, and a small amount of annual precipitation. On the contrary, there are few precipitation events in the southwest part, and the annual precipitation is large. At the same time, the maximum daily precipitation falls reasonably here. Areas with high intensity of hourly rainfall fall in the southeast, and it is necessary to pay attention to the short-term heavy rainfall in this area.

\subsection{Precipitation and probability of precipitation (POP)}



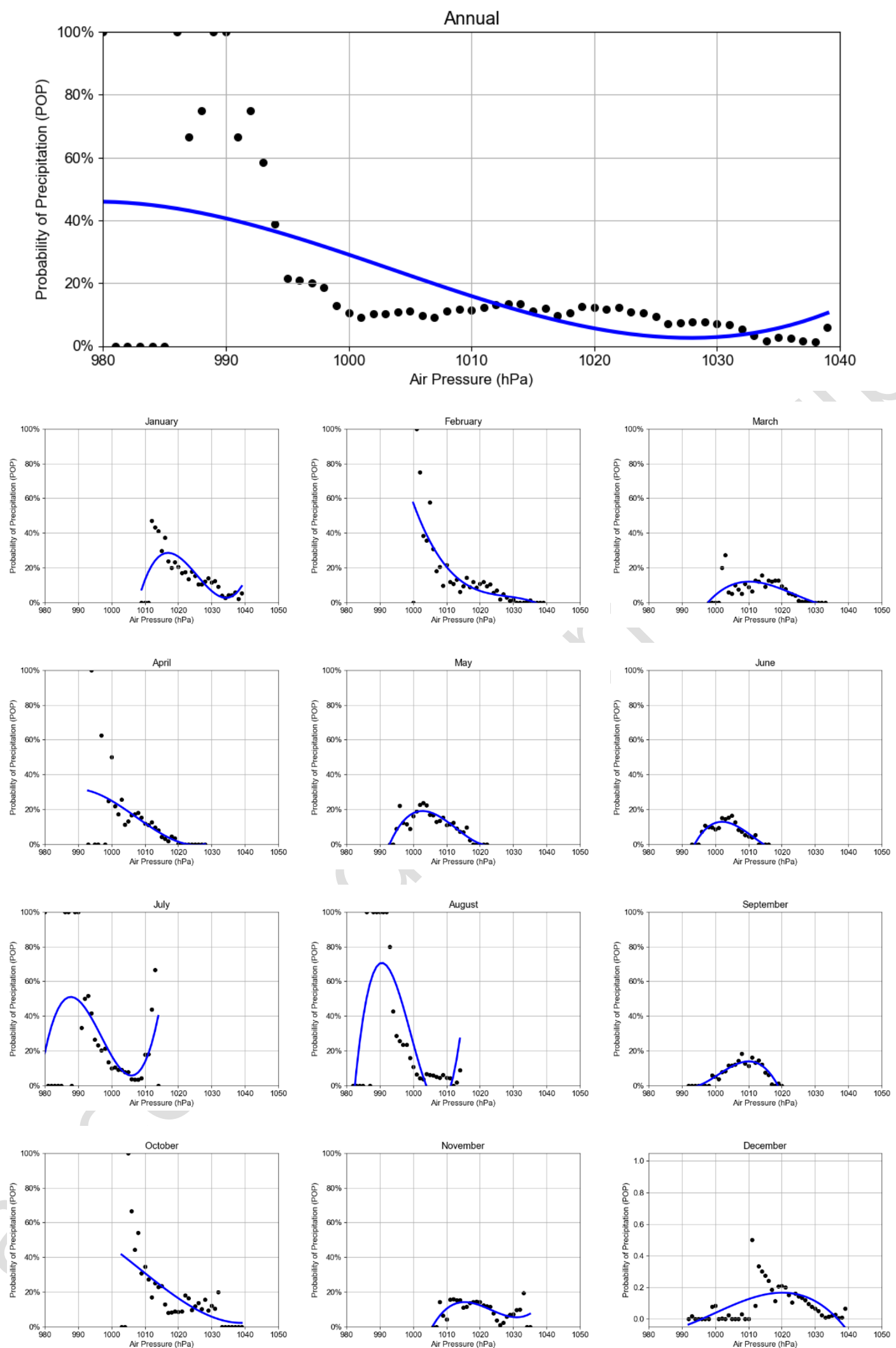

Figure 5. Relationship between air pressure and precipitation rate

Figure 5 shows the POP under different air pressures. The $\mathrm{x}$-axis and $\mathrm{y}$-axis represent that the air pressure and POP respectively. On an annual scale, the precipitation rate decreases with the increase of the pressure value. After the pressure value is higher than $1000 \mathrm{hpa}$, the precipitation rate is always lower than $20 \%$. When the pressure value is $\leqslant 986 \mathrm{hpa}$, the precipitation rate is $100 \%$. When the pressure value is higher than 
1000hpa, the precipitation rate is always lower than $20 \%$, and reaches the lowest value of $1.98 \%$ at 1034hpa.However, when the pressure value is close to $1040 \mathrm{hpa}$, the POP increases slightly. This phenomenon appears in winter (December and January). In winter, the increase in sea level temperature in the tropical Indian Ocean has become the main driving factor for the wet precipitation in the middle and lower reaches of the Yangtze River. The increase in sea level temperature in the tropical Indian Ocean has promoted the southward abnormal cyclones along the eastern coast of China, which has brought more moisture to the region (Li et al., 2015). In the summer months of July and August, this trend was broken. The intensity and position of the subtropical high in the Northwest Pacific are closely related to changes in summer precipitation (Zhang et al., 2017). Its westward extension is more conducive to the transport of strong moisture to East Asia., which lead to the continuous release of unstable energy.

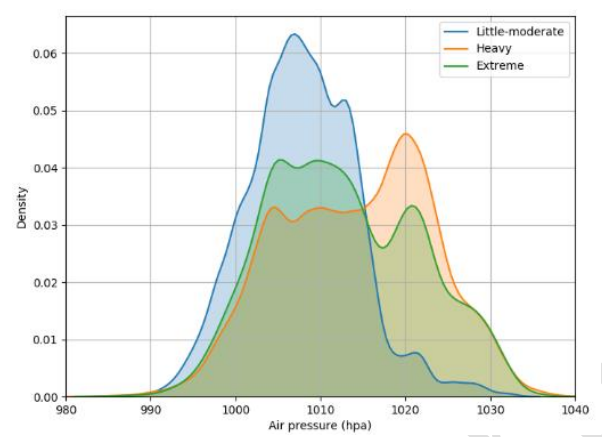

Figure 6. Pressure distribution of three types of precipitation events

Figure 6 shows the statistical distribution of air pressure when three types of precipitation events occurred in $2016 \sim 2018$. The three shaded line segments represent the ratio of air pressure to the total air pressure. The air pressure when a light rain event occurs is mostly concentrated between $1000 \mathrm{hpa}$ and $1015 \mathrm{hpa}$. The number of heavy rain events is highest when the pressure is $1020 \mathrm{hpa}$, followed by $1002 \mathrm{hpa} \sim 1015 \mathrm{hpa}$. The air pressure distribution under extreme precipitation events presents a bimodal shape, at $1004 \mathrm{hpa}$ and 1 021 hpa respectively, indicating that heavy precipitation and extreme precipitation under high-pressure air masses have a higher probability of occurrence.

\subsection{Temperature and $P O P$}

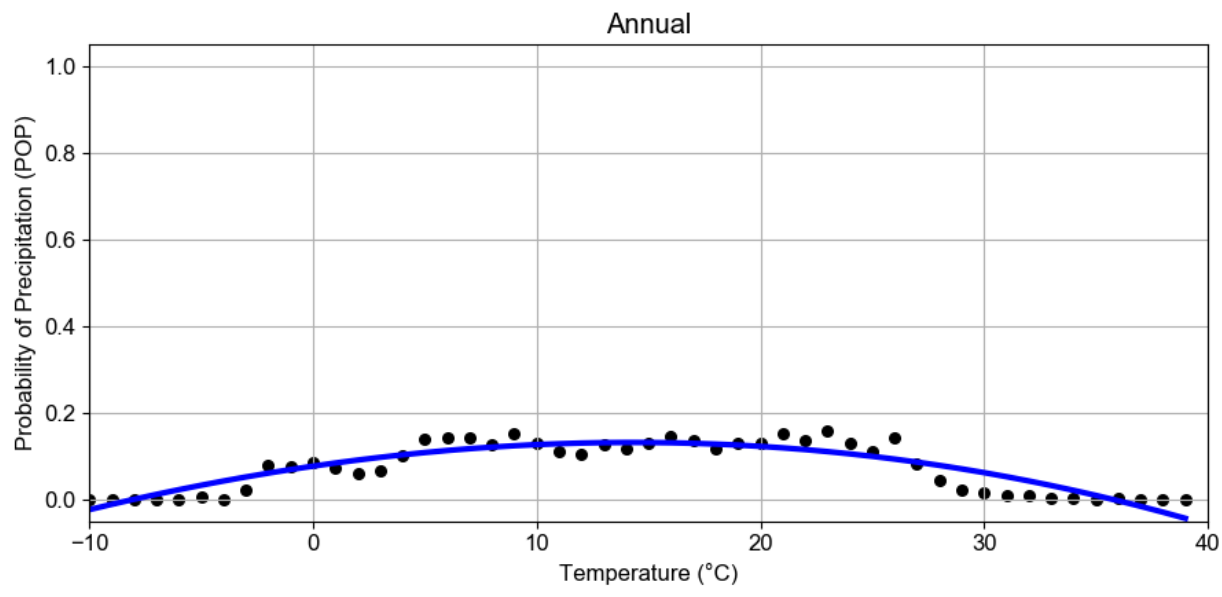



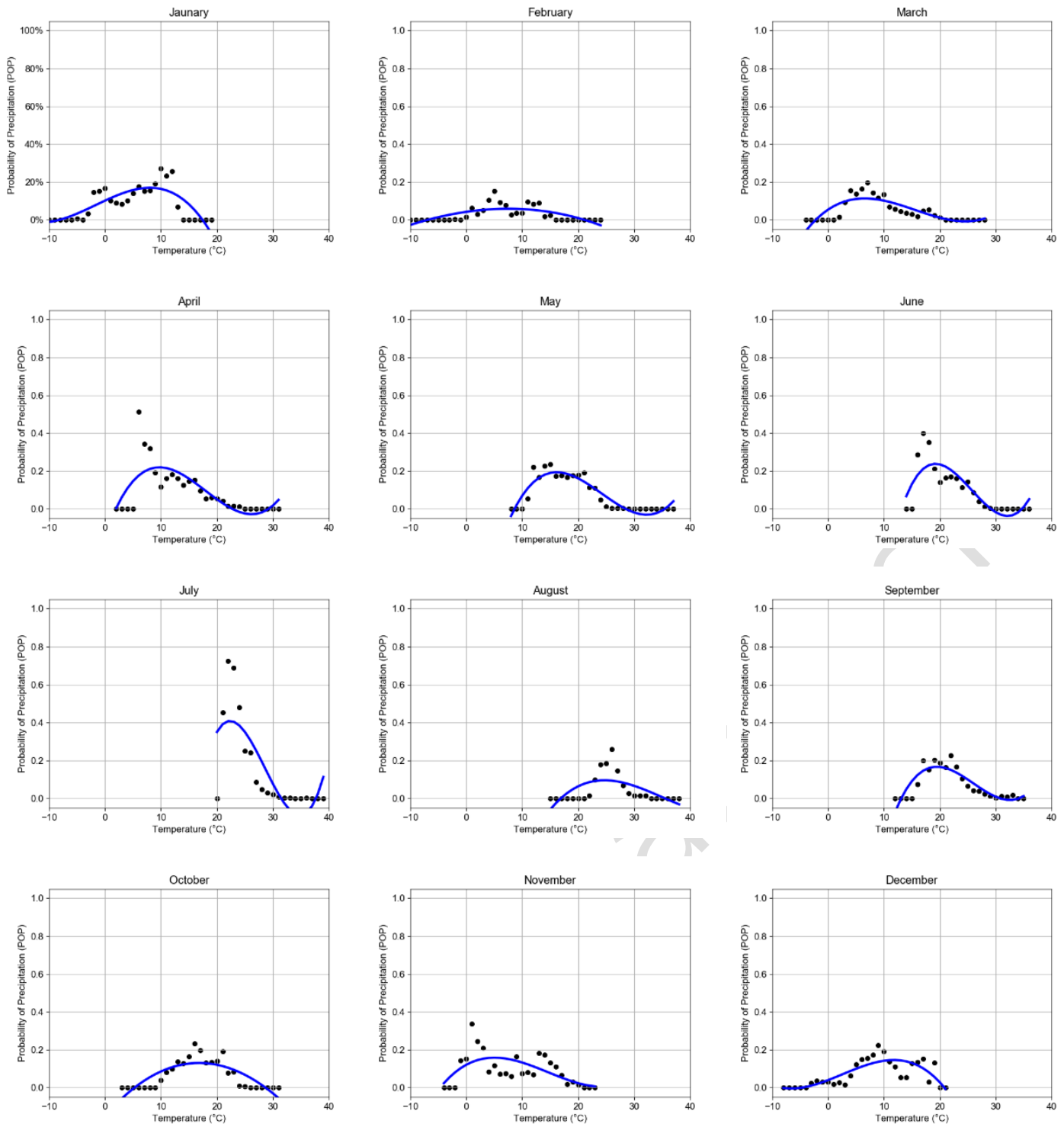

Figure 7. Relationship between temperature and precipitation rate

The top of Figure 7 is the relationship between the annual temperature and precipitation rate in 2016 2018. The temperature is between $-4^{\circ} \mathrm{C}$ and $30^{\circ} \mathrm{C}$ and precipitation occurs. The precipitation rate at all temperatures throughout the year is less than $20 \%$. Each month also follows the law of precipitation rate as low-high-low as the temperature rises, which is the same trend as the year. However, the differences within each month are more obvious, and the temperature of each month roughly follows its own fixed range. Most months of precipitation occur in locations where the temperature is relatively low, except December and January, where the blue fitting line bulges to the right. In cold winters, precipitation tends to occur at high temperatures. The precipitation rate in February and October is higher in the middle of the temperature distribution. The potential relationship between precipitation rate and temperature in each month can provide a certain reference for precipitation prediction.

\subsection{Relationship between air pressure and temperature before precipitation event}

4.4.1. The relationship between the pressure change value before the precipitation event and the temperature and its total change 


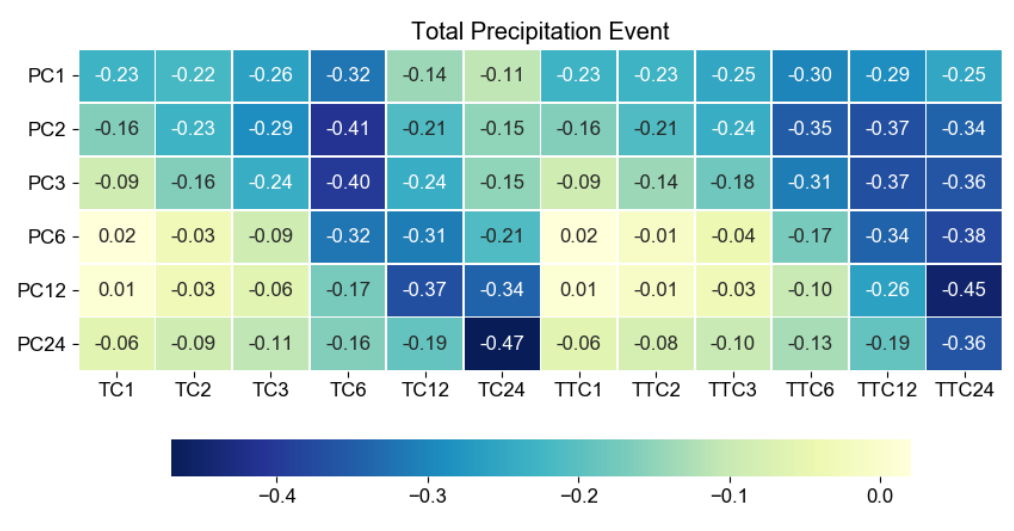

\begin{tabular}{|c|c|c|c|c|c|c|c|c|c|c|c|c|}
\hline \multirow[b]{2}{*}{$\mathrm{PC} 1-$} & \multicolumn{12}{|c|}{ Little-moderate Precipitation } \\
\hline & -0.20 & -0.20 & -0.24 & -0.31 & -0.16 & -0.11 & -0.20 & -0.21 & -0.23 & -0.29 & -0.28 & -0.26 \\
\hline $\mathrm{PC} 2-$ & -0.15 & -0.22 & -0.28 & -0.40 & -0.22 & -0.14 & -0.15 & -0.20 & -0.23 & -0.34 & -0.37 & -0.35 \\
\hline PC3 - & -0.08 & -0.16 & -0.23 & -0.40 & -0.25 & -0.15 & -0.08 & -0.13 & -0.17 & -0.30 & -0.38 & -0.37 \\
\hline PC6 - & 0.02 & -0.02 & -0.09 & -0.32 & -0.33 & -0.21 & 0.02 & -0.00 & -0.04 & -0.18 & -0.35 & -0.39 \\
\hline $\mathrm{PC} 12-$ & 0.01 & -0.03 & -0.07 & -0.19 & -0.38 & -0.35 & 0.01 & -0.01 & -0.03 & -0.11 & -0.27 & -0.46 \\
\hline $\mathrm{PC} 24-$ & -0.05 & -0.10 & -0.12 & -0.17 & -0.21 & -0.48 & -0.05 & -0.08 & -0.10 & -0.14 & -0.20 & -0.38 \\
\hline & TĆ1 & TĆ2 & TĆ3 & TĆ6 & TC'12 & TC24 & $\pi^{\prime}{ }^{\prime} \mathrm{C} 1$ & тा'C2 & тா'C3 & т'с6 & тா'́12 & тா'́24 \\
\hline
\end{tabular}
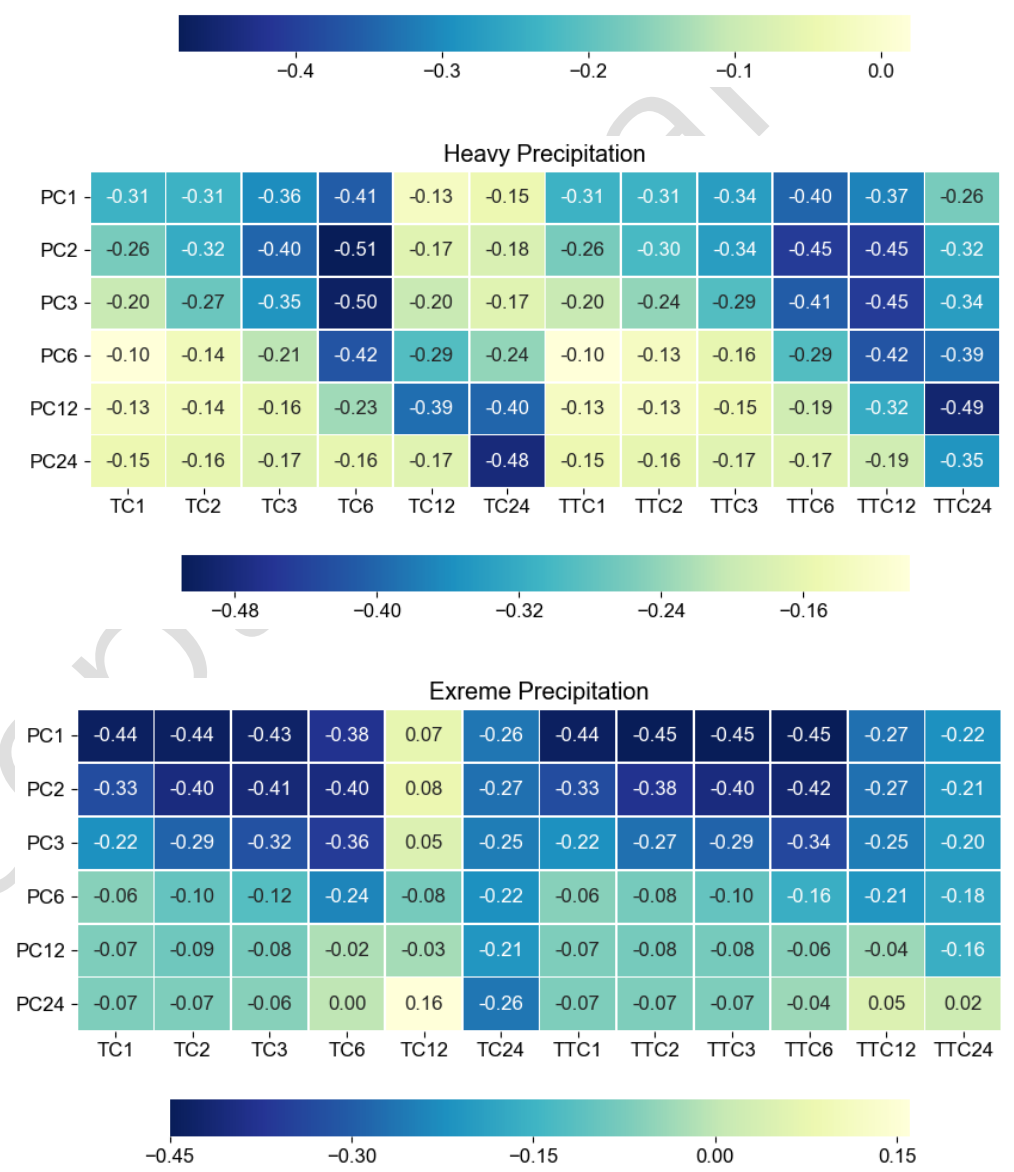

Figure 8. The correlation coefficient between the air pressure change before the event and the temperature change and the total temperature change

Figure 8 shows the strong and weak correlation between the change in air pressure and the change in temperature and the total amount of change. There is a relatively high negative difference between the temperature change in the 6 hours before the occurrence of all precipitation events and the air pressure change 
in the first 2 hours and 3 hours. It is worth noting that the pressure change value of the $12 \mathrm{~h}$ before the precipitation event has a high correlation with the total temperature change of the previous $24 \mathrm{~h}$. Since light to moderate precipitation events accounted for $91.73 \%$ of all precipitation events, Figure 7(a) shows similar values to Figure 7(b). The heavy precipitation events are divided into two situations: the pressure change value of $1 \mathrm{~h}, 2 \mathrm{~h}$ and $3 \mathrm{~h}$ has a high negative correlation with the temperature change value of $6 \mathrm{~h}$. Furthermore, the negative correlation between the total temperature change in the first 6 hours and the air pressure change in the previous 1 hour is as high as -0.64 . One to two hours before an extreme precipitation event occurs, not only is the correlation between the pressure value and the temperature value relatively high, but there is also a relatively high correlation between the pressure value and the amount of temperature change. Due to the sudden and short duration of extreme precipitation, the pressure and temperature changed drastically in the short term before the event. This is usually due to the rapid accumulation of air masses and other reasons.

4.4.2. The relationship between the total pressure change before the precipitation event and the temperature and its total change

\begin{tabular}{|c|c|c|c|c|c|c|c|c|c|c|c|c|}
\hline \multirow[b]{2}{*}{ TPC1 } & \multicolumn{12}{|c|}{ Total Precipitation Event } \\
\hline & -0.23 & -0.22 & -0.26 & -0.32 & -0.14 & -0.11 & -0.23 & -0.23 & -0.25 & -0.30 & -0.29 & -0.25 \\
\hline TPC2 - & -0.20 & -0.24 & -0.29 & -0.38 & -0.19 & -0.14 & -0.20 & -0.23 & -0.26 & -0.34 & -0.35 & -0.32 \\
\hline TPC3 - & -0.16 & -0.21 & -0.27 & -0.40 & -0.21 & -0.15 & -0.16 & -0.19 & -0.23 & -0.34 & -0.37 & -0.35 \\
\hline TPC6 - & -0.07 & -0.12 & -0.19 & -0.39 & -0.27 & -0.18 & -0.07 & -0.10 & -0.14 & -0.27 & -0.38 & -0.38 \\
\hline TPC12- & -0.01 & -0.06 & -0.11 & -0.30 & -0.37 & -0.28 & -0.01 & -0.04 & -0.07 & -0.18 & -0.35 & -0.44 \\
\hline TPC24 - & -0.01 & -0.05 & -0.08 & -0.20 & -0.29 & -0.41 & -0.01 & -0.03 & -0.05 & -0.13 & -0.25 & -0.44 \\
\hline & TĆ1 & TĆ2 & TC'3 & TC6 & TC12 & TC24 & $\pi^{\prime} \mathrm{C} 1$ & Tा'C2 & тा'C3 & тा'с6 & Tा'12 & Tा'ं 24 \\
\hline
\end{tabular}
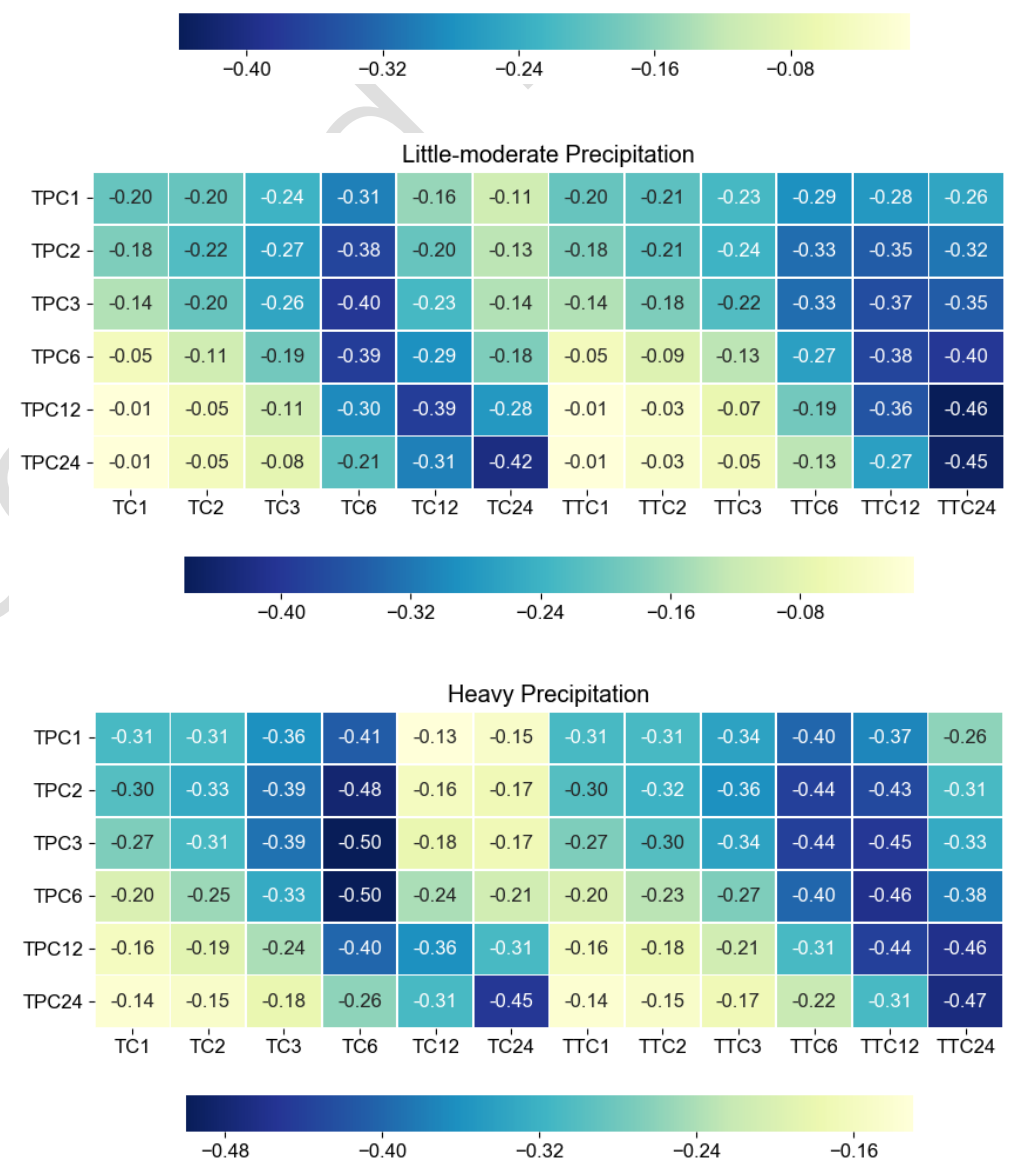


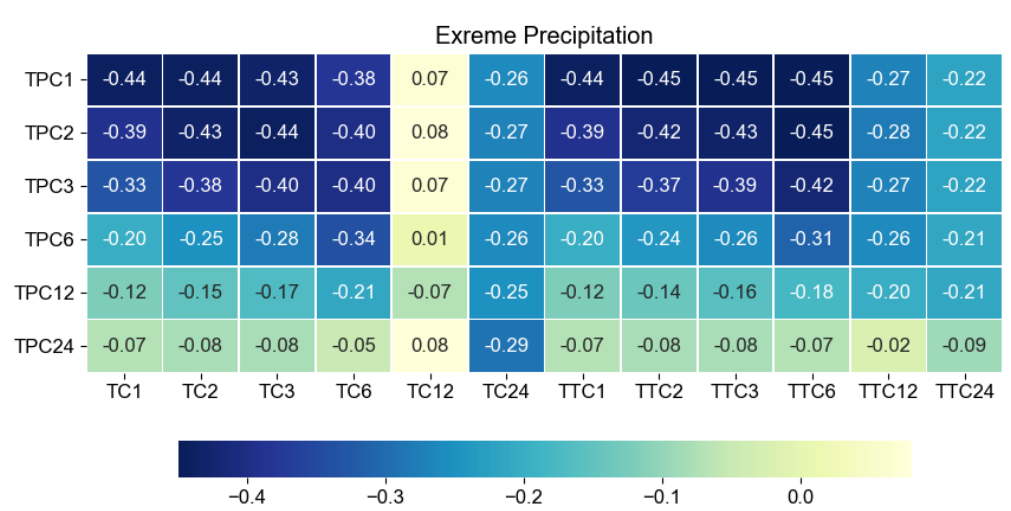

Figure 9. The correlation coefficient between the total pressure change before the event and the temperature change and the total temperature change

Figure 9 shows the correlation coefficient between the total pressure change before the precipitation event and the temperature change and the total temperature change. The similarities to Figure 7 are: 1) The calculation results of correlation coefficients for all precipitation events and light to moderate precipitation events are similar. 2) The temperature change value and total change $6 \mathrm{~h}$ before the event always have a high negative correlation with the air pressure. The correlation coefficient between the TPC, TC and the TTC shows a higher negative correlation in heavy precipitation and extreme precipitation, which has a greater change from the figure shown in Figure 7. Unexpectedly, before the occurrence of the heavy precipitation event, the correlation coefficient between the total pressure change and the total temperature change reached a strong negative correlation of -0.64 , which is helpful for predicting precipitation through the pressure change.

\section{Conclusion and discussion}

This paper studies the relationship between the change in air pressure and temperature in the 24 hours before the precipitation event on a section of the high-speed rail in 2016 2018 and the total amount of change. Through the observation of meteorological stations around the railway, the correlation between air pressure, temperature and precipitation before the occurrence of precipitation events have been found, which serves as basic research for the operation of the HSR. The conclusions are as follows:

1) For the studied areas along the railway, the annual precipitation in $2016 \sim 2018$ exceeded the historical average (Chen et al., 2014). The distribution of precipitation in the region is uneven, and the precipitation along the line section is relatively frequent and the precipitation is large. The areas with the largest daily precipitation are distributed in the southwest along the railway, but the hourly maximum precipitation intensity is concentrated in the southeast along the railway. Except for July, when the pressure value along the high-speed rail is at a relatively low level, the possibility of precipitation is higher. From a year-round scale, there is no obvious relationship between temperature and precipitation. However, from the monthly scale map drawn, the low temperatures in April, June and July have higher precipitation rates. Since the rainy season in this area is concentrated in summer, June and July are the main precipitation contributing months, and we need to pay attention to the temperature during this time period (Jiang et al., 2007). 2) Merely observing changes in temperature cannot ensure accurate changes in extreme precipitation. The changes in air pressure and air temperature before the occurrence of precipitation events are divided into three categories. The correlation between air temperature and air pressure changes before the occurrence of mild-moderate precipitation events has a large span and requires a longer period of attention. The temperature in the 6 hours before the occurrence of the heavy precipitation event has a strong correlation with the short-term pressure change. In contrast, the air pressure and temperature within 2 hours before the occurrence of extreme precipitation changes rapidly and have a strong correlation, which indicates the occurrence of extreme events. In fact, as global climate changes 
become more and more intense, extreme precipitation events have become more frequent, and severe extreme precipitation has received more and more attention (Tian et al., 2020).To explore the fluctuations of climate change within 24 hours before the occurrence of extreme precipitation to predict heavy precipitation. However, the above research is far from enough. The meteorological elements are mostly related to a moderate degree, which cannot be directly applied to the development of heavy precipitation models. In addition, In addition, the short-term climate change of 24 hours is uncertain. This short-term change of local climate needs further study.

This study shows that there is a certain law of air pressure, air temperature and its changes in a specific period of time before a precipitation event occurs, which can be found by real-time monitoring of surface air pressure and air temperature. For example, the pressure change in the $2 \mathrm{~h}$ and $3 \mathrm{~h}$ before the occurrence of a heavy precipitation event is negatively correlated with the temperature change in the previous 6 hours by above 0.5 , which is different from other precipitation events. This phenomenon is of great significance for guiding the establishment of the HSR rainwater disaster prevention system and preventing HSR floods.

It is necessary to pay attention to excessive extreme precipitation disasters and reconstruction work, but prevention in advance is often of more important significance. We look for the characteristics of precipitation along the railway line from the air pressure, temperature and precipitation data monitored on the ground, and discuss the relationship between air pressure and temperature and the amount of precipitation produced by precipitation levels. As such, the production of extreme precipitation involves more multi-scale dynamics and microphysical processes (Chern et al., 2020; Endo and Kitoh, 2014). How to build a bridge between ground observations and physical processes requires further research.

\section{Acknowledgments}

This research was partially supported by Natural Science Foundation of Jiangsu Province under Grant no. BK20210661; Talent Startup Project of Nanjing University of Information Science and Technology under Grant no. 2243141701053; General program of natural science research in Jiangsu Province (19KJB170004); Key scientific research projects of China State Railway Group Co., Ltd (N2019T003).

\section{References}

Bocheva, L., Marinova, T., Simeonov, P., et al. (2009). Variability and trends of extreme precipitation events over Bulgaria (1961-2005). Atmospheric Research, 93(1-3): 490-497.

Chen, J., Wu, X., Finlayson, B.L., et al. (2014). Variability and trend in the hydrology of the Yangtze River, China: Annual precipitation and runoff. Journal of Hydrology, 513: 403-412.

Chen, Y., Zhai, P. (2013). Persistent extreme precipitation events in China during 1951-2010. Climate Research, 57(2): 143-155.

Chern, J.D., Tao, W.K., Lang, S.E., et al. (2020). Evaluating precipitation features and rainfall characteristics in a multi-scale modeling framework. Journal of Advances in Modeling Earth Systems, 12(8): e2019MS002007.

Durkee, J.D., Campbell, L., Berry, K., et al. (2012). A synoptic perspective of the record 1-2 May 2010 Midsouth heavy precipitation event. Bulletin of the American Meteorological Society, 93(5): 611-620.

Endo, H., Kitoh, A. (2014). Thermodynamic and dynamic effects on regional monsoon rainfall changes in a warmer climate. Geophysical Research Letters, 41(5): 1704-1711.

Guo, W., Zeng, C., Gou, H., et al. (2019). Rotational friction damper's performance for controlling seismic response of high speed railway bridge-track system. Computer Modeling in Engineering \& Sciences, 120(3): 491-515.

Hina, S., Saleem, F., Arshad, A., et al. (2021). Droughts over Pakistan: possible cycles, precursors and associated mechanisms. Geomatics, Natural Hazards and Risk, 12(1): 1638-1668. 
Hu, Q., Bian, L., Tan, M. (2020). A data perception model for the safe operation of high-speed rail in rainstorms. Transportation research part D: Transport and Environment, 102326.

Jennrich G.C., Furtado J.C., Basara J.B., et al. (2020). Synoptic Characteristics of 14-Day Extreme Precipitation Events across the United States. Journal of Climate, 33(15): 6423-6440.

Jiang, T., Su, B., Hartmann, H. Temporal and spatial trends of precipitation and river flow in the Yangtze River Basin, 1961-2000. Geomorphology. 2007, 85(3-4): 143-154.

Kunkel, K.E., Easterling, D.R., Kristovich, D.A.R., et al. (2012). Meteorological causes of the secular variations in observed extreme precipitation events for the conterminous United States. Journal of Hydrometeorology, 13(3): 1131-1141.

Lehmann, J., Coumou, D., Frieler, K. (2015). Increased record-breaking precipitation events under global warming. Climatic Change, 132(4): 501-515.

Li, X.F., Li, J., Li, Y. (2015). Recent winter precipitation increase in the middle-lower Yangtze River valley since the Late 1970s: A response to warming in the tropical Indian ocean. Journal of Climate, 28(9): 38573879 .

Liebmann, B., Jones, C., de Carvalho, L.M.V. (2001). Interannual variability of daily extreme precipitation events in the state of Sao Paulo, Brazil. Journal of Climate, 14(2): 208-218.

Niu, X., Wang, S., Tang, J., et al. (2018). Ensemble evaluation and projection of climate extremes in China using RMIP models, 38(4): 2039-2055.

Pishtiwan, A.H., Khadija, K.M. (2019). Molecular identification of clinical microbes in thalassemia patients using 16s RRNA gene sequencing. Applied Ecology and Environmental Research, 17(6): 13135-13146.

Ren, X., Chen, Z., Wang, F., et al. (2020). Impact of high-speed rail on social equity in China: Evidence from a mode choice survey. Transportation Research Part A: Policy and Practice, 138: 422-41.

Shi, X., Durran, D. (2016). Sensitivities of extreme precipitation to global warming are lower over mountains than over oceans and plains. Journal of Climate, 29(13): 4779-4791.

Skrypnyk, R., Ekh, M., Nielsen, J.C., et al. (2019). Prediction of plastic deformation and wear in railway crossings-Comparing the performance of two rail steel grades. Wear, 428: 302-14.

Teixeira, J., Carvalho, A., Carvalho, M., et al. (2014). Sensitivity of the WRF model to the lower boundary in an extreme precipitation event-Madeira island case study. Natural Hazards and Earth System Sciences, 14(8): 2009.

Tian, P., Lu, H., Feng, W., et al. (2020). Large decrease in streamflow and sediment load of Qinghai-Tibetan Plateau driven by future climate change: A case study in Lhasa River Basin. Catena (Giessen), 187: 104340.

Trenberth, K.E., Dai, A., Rasmussen, R.M., et al. (2003). The changing character of precipitation. Bulletin of the American Meteorological Society, 84(9): 1205-1218.

Twumasi, N.Y.D., Shao, Z., Altan, O. (2019). Mapping built-up areas using two band ratio on Landsat imagery of Accra in Ghana from 1980 to 2017. Applied Ecology and Environmental Research, 17(6): 13147-13168.

Wan, B., Gao, Z., Chen, F., et al. (2017). Impact of Tibetan Plateau surface heating on persistent extreme precipitation events in Southeastern China. Monthly Weather Review, 145(9): 3485-3505.

Wang, H., He, J., Wei, M., et al. (2015). Synthesis analysis of one severe convection precipitation event in Jiangsu using ground-based GPS technology. Atmosphere, 6(7): 908-927.

Xiao, S., Oladyshkin, S., Nowak, W. (2020). Reliability analysis with stratified importance sampling based on adaptive Kriging. Reliability Engineering \& System Safety, 197: 106852.

Xu, Q., Zou, Z.W., Chen, Y.S., et al. (2020). Performance of a novel-type of heat flue in a coke oven based on high-temperature and low-oxygen diffusion combustion technology. Fuel (Guildford), 267(C): 117160.

Yao, C., Yang, S., Qian, W., et al. (2008). Regional summer precipitation events in Asia and their changes in the past decades. Journal of Geophysical Research: Atmospheres, 113(D17). 
Yao, C., Yang, S., Qian, W., et al. (2008). Regional summer precipitation events in Asia and their changes in the past decades. Journal of Geophysical Research: Atmospheres, 113(D17).

Yu, Z., Miller, S., Montalto, F., et al. (2018). The bridge between precipitation and temperature-Pressure Change Events: Modeling future non-stationary precipitation. Journal of Hydrology, 562: 346-357.

Zhang, Q., Zheng, Y., Singh, V.P., et al. (2017). Summer extreme precipitation in eastern China: mechanisms and impacts. Journal of Geophysical Research: Atmospheres, 122(5): 2766-2778.

Zhang, X., Hogg, W.D., Mekis, É. (2001). Spatial and temporal characteristics of heavy precipitation events over Canada. Journal of Climate, 14(9): 1923-1936.

Zheng, J., Zhao, H. (2005). Variation of seasonal precipitation and extreme events in Jiangsu Province during 1736-1908. Geographical Research, 5.

Zuo, X., Dong, M., Gao, F., et al. (2020). The modeling of the electric heating and cooling system of the integrated energy system in the coastal area. Journal of Coastal Research, 103(sp1): 1022. 